\title{
Born to kill: Predatory functional responses of the littoral amphipod Echinogammarus marinus Leach throughout its life history
}

\author{
Mhairi E. Alexander ${ }^{\mathrm{a}, *}$, Jaimie T.A. Dick ${ }^{\mathrm{a}, \mathrm{b}}$, Nessa E. O'Connor ${ }^{\mathrm{a}}$ \\ a School of Biological Sciences, Queen's University Belfast, MBC, 97 Lisburn Road, Belfast, BT9 7BL, Northern Ireland, UK \\ ${ }^{\mathrm{b}}$ Centre for Invasion Biology, Department of Botany \& Zoology, Stellenbosch University, Private Bag X1, Matieland 7602, South Africa
}

\section{A R T I C L E I N F O}

Article history:

Received 11 July 2012

Received in revised form 5 October 2012

Accepted 8 October 2012

Available online 13 November 2012

\section{Keywords:}

Amphipod

Functional response

Habitat complexity

Ontogeny

Predation

\begin{abstract}
A B S T R A C T
Studies of predator-prey interactions, and in particular the derivation of functional responses, have typically focussed on adults or single life-history stages, with subsequent food web analyses often simply using average body sizes or assuming that all conspecifics are equal. Such limited consideration of ontogeny in the context of predatory functional responses may have important implications for our understanding of community structure and function. Further, large predators may be physically restricted in their ability to feed on very small prey individuals and/or avoid such predation due to its limited energetic return. Here, we elucidate the predatory nature and impact of the marine intertidal amphipod, Echinogammarus marinus, throughout its ontogeny, towards a prey species, the isopod Jaera nordmanni. Firstly, we found J. nordmanni in the guts of field caught E. marinus, from juveniles through to adults of the latter, indicating that $E$. marinus may be predatory throughout ontogeny. Secondly, juvenile, sub-adult and adult E. marinus exhibited Type II functional responses towards size-matched J. nordmanni prey. In addition, the largest adult E. marinus fed on the smallest J. nordmanni, again with Type II functional responses, in both homo- and heterogeneous habitat. Thus, the prey do not benefit from any ontogenetic or size refuge from the predator. These findings demonstrate the significant predatory ability and potential population level impacts of E. marinus throughout its ontogeny, which may determine local prey species exclusion and persistence. Determining the functional responses of predators throughout their ontogeny may thus improve our understanding and prediction of their community impacts.
\end{abstract}

(c) 2012 Elsevier B.V. All rights reserved.

\section{Introduction}

The extent to which a prey population is impacted by a predator is dependent on a range of abiotic and biotic factors, such as habitat type and heterogeneity (e.g. Almany, 2004; Swisher et al., 1998; Warfe and Barmuta, 2004; Werner and Hall, 1988), and behavioural characteristics relating to both the predator and prey, such as aggregation behaviour, activity levels and refuge use (e.g. Côté and Jelnikar, 1999; Jennions et al., 2003; Turner, 2008). Further to this, the ontogeny of predatory disposition and ability can be important in understanding predator impacts on prey populations throughout the course of a predator's life history (Céréghino, 2006; Dick et al., 2012a). This is particularly important to resolve, as food web studies often assume, for reasons of tractability, that all conspecifics have identical characteristics, or use average body sizes (Woodward and Warren 2007). Although in some species there are limited dietary changes that occur throughout ontogeny (Werner and Gilliam, 1984), in others resource use may alter continuously throughout an individual's life-history (Hanquet et al., 2004). Generally, size and

\footnotetext{
* Corresponding author. Tel.: +44 289097 2030; fax: + 442890975877.

E-mail address: malexander06@qub.ac.uk (M.E. Alexander).
}

type of prey consumed vary as a consequence of increasing body size with age (Morato et al., 2000; Wilson, 1975), and larger prey are advantageous for growing predators, possibly reflecting the decreased nutritional importance of smaller sized foods (Graeb et al., 2006). Predation on larger prey may also be a reflection of an increase in size and power of feeding apparatus as a predator matures, such as the development of chelae and mouthparts allowing a predator to select otherwise inaccessible prey (O'Brien, 1994). Small prey may therefore experience a size refuge from larger predators, however, this may be of little consequence if smaller predators also consume these smaller prey (St John, 1999). Further, larger predators may or may not be physically able to consume small prey (e.g. Rindone and Eggleston, 2011), and with the body size ratio among certain predators and prey shown to determine interaction strengths (Emmerson and Raffaelli, 2004), there are potential consequences for prey population size and stability (O'Gorman and Emmerson, 2011). Subsequently, such dynamic shifts in resource use may complicate species interactions, with important consequences for community dynamics and prey population stability (Woodward and Hildrew, 2002).

The functional response, describing the relationship between the number of prey consumed and the initial prey density (Holling, 1959), 
provides insights into predator-prey interactions and is often used as a measure of feeding capability to elucidate predator effects on prey population stability (Miller et al., 1992; Rindone and Eggleston, 2011; Wennhage, 2002). In general, three forms of the functional response are considered, each with a different contribution to prey population stability: (1) the Type I, linear, density-independent response, with consumption reaching an abrupt plateau due to handling constraints (2) the Type II, inversely density-dependent response, where most prey are consumed at low prey densities and consumption rises at a decelerating rate to an asymptote, again perhaps due to handling time constraints; and (3) the Type III, density-dependent response, which is sigmoidal due to low prey consumption at low prey densities, perhaps due to significant search time when prey density is low or predator switching behaviour (Hassell, 1978). Type II functional responses are likely to de-stabilise prey populations, as there is little or no refuge for prey at low prey densities as occurs with the more stabilising Type III functional response (Colton, 1987; Hassell, 1978; Murdoch and Oaten, 1975). Despite the fact that ontogenetic changes in predator-prey interactions are well documented in the literature, few studies have featured functional responses in such an ontogenetic context (but see Elliot, 2005; Fox and Murdoch, 1978; McCoy and Bolker, 2008; Miller et al., 1992; Thompson, 1975).

This study investigated the ontogeny of the functional response of a marine intertidal amphipod, Echinogammarus marinus. On rocky intertidal shores, recognition of the predatory role of amphipods is emerging (Ingólfsson and Agnarsson, 1999), and E. marinus has recently been demonstrated to be an active predator, consuming a range of prey species (Alexander et al., in press; Dick et al., 2005). What is unknown, however, is whether this amphipod exhibits a predatory role throughout its ontogeny. With a number of species of amphipods observed to have major structuring effect on macroalgal communities (Brawley and Adey, 1981; Duffy and Hay, 2000), it is therefore considered that they may also impose such structuring effects on invertebrate communities. These structuring effects may be even stronger if the amphipod is an active predator from juvenile through to adult life stages. Further, it is important to resolve if small prey experience a refuge from larger predators, as detailed above, which can promote prey persistence (Rindone and Eggleston, 2011).

The aim of this study was thus to determine the predatory ability and impacts of $E$. marinus throughout its ontogeny in marine intertidal communities, by describing and quantifying its functional responses towards a common prey species, the isopod Jaera nordmanni. The specific aims were to establish if: (1) by examining gut contents, E. marinus shows consumption of prey over the course of its life-history, from juvenile through to adult; (2) the shape and magnitude of the functional response differs among predators and prey scaled for body size throughout ontogeny; (3) small prey experience a size refuge from the largest adult predators; and (4) whether habitat complexity provides small prey with a refuge from predation by larger predators.

\section{Materials and methods}

\subsection{Collection and maintenance of animals}

Animal collections took place in April and May 2012 by searching under cobbles on 'Walter's Shore' at Portaferry, Northern Ireland $\left(54^{\circ} 22.9^{\prime} \mathrm{N}, 5^{\circ} 33.3^{\prime} \mathrm{W}\right)$. E. marinus for gut contents analysis were immediately killed in carbonated water, to cease digestion processes, and dissected within 3 h (see Dunn and Dick, 1998). E. marinus and J. nordmanni for experiments were transported to Queen's University Belfast and housed separately in tanks with sand-filtered seawater that was aerated with the addition of an air stone. Animals were provided with algae (Fucus serratus from the collection site) and fish food pellets (comprised of fish, mollusc and algal derivatives) at $12{ }^{\circ} \mathrm{C}$ and $12: 12 \mathrm{~h}$ light:dark, and were maintained in the laboratory for $48 \mathrm{~h}$ before use in experiments (pilot studies and previous work indicated that this was an adequate period for acclimatisation; e.g. see Alexander et al., in press). We measured body lengths of both $E$. marinus and J. nordmanni as the distance from the base of the antennae to the base of the telson. E. marinus were then sorted into three size/ developmental stages; juvenile, sub-adult and adult (3, 9, $15 \mathrm{~mm}$ respectively, all $\pm 1 \mathrm{~mm}$ ). Juveniles were defined as those having recently emerged from the female brood pouch (juveniles begin to leave at $1.5-2 \mathrm{~mm}$ in length; $\mathrm{M}$. Alexander, personal observation); sub-adults as those significantly larger but with no oostegites (female brood plates) and of a size never found in the precopulatory mate guarding phase; and adults as having oostegites (females) or genital papillae (males) and of sizes found in precopula. J. nordmanni were sorted into size classes of $0.8,2.4$ and $4 \mathrm{~mm}( \pm 0.3 \mathrm{~mm})$. This allowed us to size match predator and prey, maintaining a body length ratio of 3.75 .

\subsection{Gut content analysis}

E. marinus of each size class above ( $n=10$ each) were starved individually in plastic containers ( $5 \mathrm{~cm}$ diameter; $100 \mathrm{ml}$ seawater) for 7 days to ensure their guts were fully evacuated (see Dick et al., 2005). Each was then presented with 10 size matched J. nordmanni prey as above. Once a prey item had been consumed, each E. marinus was killed in carbonated water and its gut immediately dissected and examined. This provided a prey signature with which to compare gut contents of individuals collected in the field. Then, 118 such E. marinus (juveniles, $n=39$; sub-adults, $n=41$; adults, $n=38$ ) were dissected and compared to the reference signature samples. Presence or absence of J. nordmanni in the gut of field preserved E. marinus was thus determined. Chi-squared analyses were conducted on the raw count data to test for differences in the frequency of occurrence of J. nordmanni in gut contents between male and female E. marinus and among the different life-history stages.

\subsection{Functional response experiments}

In experiment 1 , individual juvenile, sub-adult and adult $E$. marinus were presented with size matched J. nordmanni prey in experimental arenas (round plastic dishes) scaled for the three size classes of predator, that is, dish diameter was $6.5 \times$ the predator body length and seawater depth was $3 \times$ the predator body length. E. marinus were of mixed sex, as we show below that males and females from the field did not differ in frequency of $J$. nordmanni in their guts. E. marinus were starved for $24 \mathrm{~h}$ to standardise hunger levels (see Alexander et al., in press) and then presented with J. nordmanni prey at six prey densities $(2,4,8,16,30,40$ per dish; $n=6$ per experimental group) in a fully randomised design that was completed over four weeks. Predators and prey were used only once, and controls were J. nordmanni at each prey density in the absence of $E$. marinus ( $n=6$ per control group).

In experiment 2 , adult $E$. marinus were provided with the smallest J. nordmanni prey (as above) in habitat that was either 'simple' (no stones) or 'complex' (supplied with 10 stones of $10 \mathrm{~mm}$ length haphazardly scattered on the bottom of the arena), with prey densities and replication as before. Controls were J. nordmanni at each density ( $n=6$ each), with and without habitat complexity, in the absence of E. marinus. All replicates in both experiments were initiated at $17.00 \mathrm{~h}$ and prey consumption was examined after $24 \mathrm{~h}$.

In experiment 1 , mean numbers of prey dead (i.e. those consumed in the experimental groups with predators, or those dying for other reasons in the control groups without predators) were examined with respect to 'predator status' (present or absent), 'ontogenetic stage' (juvenile, sub-adult or adult E. marinus) and 'initial prey density' (as above) in a three-factor ANOVA with Tukey's post hoc tests. In the second experiment, mean numbers of prey dead (as above) were examined with respect to 'predator status' (present or absent), 'habitat' ( simple or complex) and 'initial prey density' (as 
above) in a three-factor ANOVA with Tukey's post hoc tests. In both experiments, analyses were performed on $\log _{10}(x+1)$ data; although transformed data did not conform to normality (ShapiroWilks $W$-test, $p<0.05$ ), variances were homogeneous throughout (Fligner-Killeen test, $p>0.05$ ), and ANOVA is robust to deviations from normality, particularly when, as in these analyses, the designs are balanced with a relatively large number of replicates (Underwood, 1997). Figures show untransformed means for clarity. All statistical analyses described above and below were performed using the statistical software R, version 2.14.1 (R Development Core Team, 2011).

\subsection{Functional response analyses}

There are numerous modelling approaches to the assessment of functional responses and choice of model may depend on whether a particular study is mechanistic or phenomenological in approach (Jeschke et al., 2002). Thus, the mechanistic application of parameters such as attack rate and handling time must be approached with extreme caution, or be supported with empirical measurements of parameter estimates (Caldow and Furness, 2001; Jeschke and Hohberg, 2008; Jeschke et al., 2002). Phenomenological use of these parameters does, however, provide a tool to examine differences in functional response types and parameter estimates in comparative or factorial experiments and this is the approach taken here.

Logistic regression of the proportion of prey killed as a function of prey density was used to distinguish between Type II and III functional responses (Juliano, 2001; Trexler et al., 1988). Logistic regression models were fitted using maximum likelihood estimation and a binomial error distribution. A significantly negative first order term indicates a Type II response, whereas a significantly positive first order term, followed by a significantly negative second order term, indicates a Type III response (Juliano, 2001). The 'random predator equation' (Rogers, 1972) was fitted to our data as is appropriate for experiments where prey deplete over time and are not replaced upon consumption (Juliano, 2001);

$N_{e}=N_{0}\left(1-\exp \left(a\left(N_{e} h-T\right)\right)\right)$

where $N_{e}$ is the number of prey eaten, $N_{0}$ is the initial density of prey, $a$ is the attack constant, $h$ is the handling time and $T$ is the total time available. Maximum feeding rate was estimated as $1 / h T$. Due to the implicit nature of the random predator equation, the Lambert $\mathrm{W}$ function was implemented to fit the model to the data (Bolker, 2010). Bootstrapping was used to generate multiple estimates $(n=20)$ of the attack rate $a$, handling time $h$ and maximum feeding rate $1 / h T$ for statistical significance testing. In experiment 1 , mean parameter estimates were examined with respect to 'ontogenetic stage' (juvenile, sub-adult and adult E. marinus) in a one-factor ANOVA with Tukey's post hoc tests. In the second experiment, mean parameter estimates were examined with respect to 'habitat' (simple or complex) in a one-factor ANOVA with Tukey's post hoc tests. Analyses were performed on untransformed data.

\section{Results}

\subsection{Gut content analysis}

The signature of $J$. nordmanni in the guts of experimentally fed E. marinus appeared as dark brown/grey material with clear portions of undigested pieces of isopod exoskeleton. This was easily related to field preserved individuals, as other food in their guts took on quite a different appearance from the J. nordmanni signature. Material that was considered to be different prey species had a much lighter appearance, and algal matter, green algae in particular, was identifiable due to its distinct colouration. Relating this to field preserved E. marinus revealed that all size classes of E. marinus had recently consumed J. nordmanni: $15 \%$ of juveniles ( 6 of 39 ); $34 \%$ of sub-adults (14 of 41 ); and $57 \%$ of adults (12 of 19 females and 10 of 19 males). There was no significant difference in the frequency of $J$. nordmanni in E. marinus guts between males and females $\left(\chi^{2}=0.4\right.$, d.f. $\left.=1, \mathrm{NS}\right)$, but this did increase significantly moving from juvenile, through sub-adult to adult $\left(\chi^{2}=15.3\right.$, d.f. $=2, P<0.001)$.

\subsection{Experiment 1}

We directly observed all ontogenetic stages of E. marinus actively pursuing, capturing, killing and consuming J. nordmanni and such predation was further evidenced by prey body parts littering the aquaria floors. Further, control J. nordmanni (no predator present) of each size class had $>99 \%$ survival after 24 h. Overall, mean J. nordmanni deaths were significantly higher when $E$. marinus was present as compared to absent (Table 1a). There was a significant effect of 'ontogenetic stage' (Table 1a; Fig. 1a), with significantly fewer deaths in the juvenile group compared to the adult and sub-adult groups (Tukey's test, $P<0.05$; Fig. 1). However, for all E. marinus ontogenetic stages and prey densities, more prey died in the presence of $E$. marinus than in controls (Tukey's test, all $P<0.001$ ); that is, all life history stages of E. marinus reduced prey numbers significantly. There was also significantly more prey consumption at higher prey densities (Table 1a; Fig. 1a). A significant 'predator status x ontogenetic stage' interaction (Table 1a; Fig. 1a) resulted from higher prey consumption relative to controls moving from juvenile through to adult (Tukey's test, all $P<0.001)$ and a significant 'predator status $\times$ density' interaction (Table 1a; Fig. 1a) occurred due to greater disparities in deaths between experimental and control groups at higher densities (reflecting the $<1 \%$ deaths of prey when predators were absent).

At each predator ontogenetic stage, logistic regression indicated that E. marinus exhibited Type II functional responses towards J. nordmanni, as revealed by the significantly negative linear coefficients (Table 2a; Fig. 1a and b). Mean attack rate $a$ was significantly greater for subadults in comparison to both juvenile and adult predators (Table 3a; Tukey's test, all $P<0.001$; Fig. 2a). Mean handling time $h$ was significantly higher for juvenile predators compared to sub-adult and adults (Table 3a; Tukey's test, all $P<0.001$; Fig. 2b). Mean maximum feeding rate $1 / h T$ was significantly different among each of the ontogenetic stages and was lowest in juveniles and greatest in adults (Table 3a; Tukey's test, all $P<0.001$; Fig. 2c).

\section{Table 1}

Three-way ANOVAs on number of $J$. nordmanni consumed $\left(\log _{10}(\mathrm{x}+1)\right.$ transformed in (a) Experiment 1 with the factors 'predator status' (present or absent), 'ontogenetic stage' (juvenile, sub-adult and adult) and 'initial prey density' $(2,4,8,16,30,40)$ and (b) Experiment 2 with the factors 'predator status' (present or absent), 'habitat' (simple or complex) and 'initial prey density' $(2,4,8,16,30,40)$. Significant $P$-values in bold, $\alpha=0.05$.

\begin{tabular}{lrrrr}
\hline Source of variation & $d f$ & \multicolumn{1}{l}{ MS } & \multicolumn{1}{l}{$F$} \\
\hline a) Experiment 1 & 1 & 14.190 & 447.394 & $<\mathbf{0 . 0 0 1}$ \\
Predator status & 2 & 0.320 & 10.077 & $<\mathbf{0 . 0 0 1}$ \\
Ontogenetic stage & 5 & 0.299 & 9.412 & $<\mathbf{0 . 0 0 1}$ \\
Prey density & 2 & 0.361 & 11.384 & $<\mathbf{0 . 0 0 1}$ \\
Predator status $\times$ Ontogenetic stage & 5 & 0.200 & 6.309 & $<\mathbf{0 . 0 0 1}$ \\
Predator status $\times$ Prey density & 10 & 0.026 & 0.807 & 0.622 \\
Ontogenetic stage $\times$ Prey density & 10 & 0.027 & 0.862 & 0.507 \\
Predator status $\times$ Ontogenetic & & & & \\
$\quad$ stage $\times$ Prey density & 180 & 0.032 & & \\
Error & & & & \\
b) Experiment 2 & 1 & 8.550 & 201.315 & $<\mathbf{0 . 0 0 1}$ \\
Predator status & 1 & 1.613 & 37.975 & $<\mathbf{0 . 0 0 1}$ \\
Habitat & 5 & 0.415 & 9.779 & $<\mathbf{0 . 0 0 1}$ \\
Prey density & 1 & 1.551 & 36.526 & $<\mathbf{0 . 0 0 1}$ \\
Predator status $\times$ Habitat & 5 & 0.334 & 7.861 & $<\mathbf{0 . 0 0 1}$ \\
Predator status $\times$ Prey density & 5 & 0.034 & 0.794 & 0.556 \\
Habitat $\times$ Prey density & 5 & 0.039 & 0.911 & 0.477 \\
Predator status $\times$ Habitat $\times$ Prey density & 120 & 0.042 & & \\
Error & & &
\end{tabular}



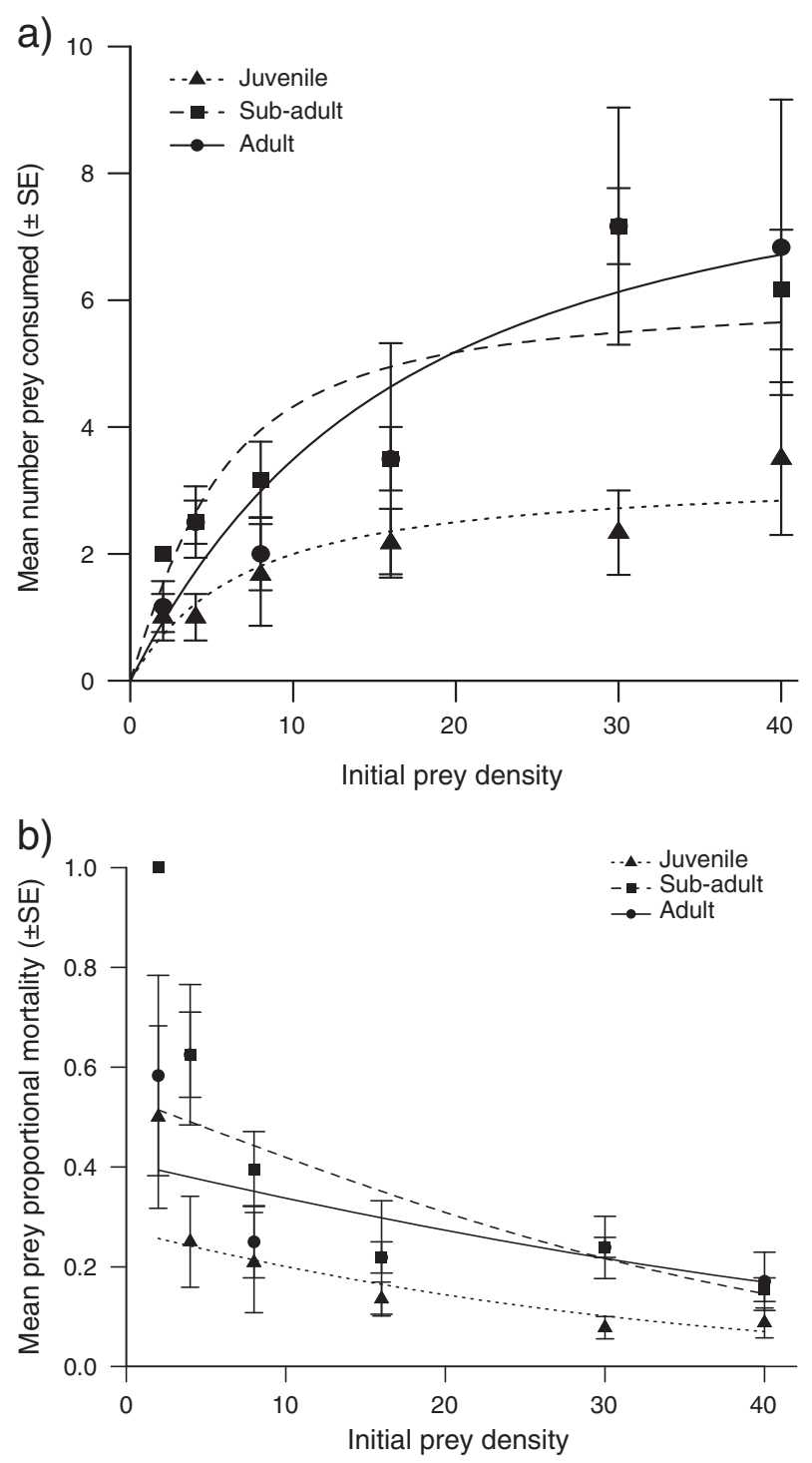

Fig. 1. (a) Functional responses of juvenile, sub-adult and adult E. marinus towards size matched J. nordmanni. Means are numbers of prey at each density, presented \pm SE. The sizes of predators, prey and arenas were scaled (see text for details). (b) Proportional mortality of $J$. nordmanni under predation from juvenile, sub-adult and adult E. marinus. Means are proportion of prey consumed at each prey density, presented with $\pm \mathrm{SE}$, and curves generated from first-order logistic regression analysis.

Table 2

Parameter estimates (and significance levels) from logistic regression analyses of proportion of prey killed against initial prey density. Analyses were determined for interactions occurring in (a) Experiment 1 for different ontogenetic stages of E. marinus with prey scaled for predator size, and (b) Experiment 2 for large predators and small prey in simple and complex habitats; values for the intercept and first-order $\left(N_{0}\right)$ terms are presented with $P$ values. Significant $P$-values in bold, $\alpha=0.05$.

\begin{tabular}{|c|c|c|c|c|}
\hline & & $\begin{array}{l}\text { Intercept } \\
\text { ( } P \text { value })\end{array}$ & $\begin{array}{l}N_{0} \\
(P \text { value })\end{array}$ & $\begin{array}{l}\text { Functional } \\
\text { response type }\end{array}$ \\
\hline \multirow[t]{3}{*}{ (a) Experiment 1} & Juvenile & $\begin{array}{l}-0.9823 \\
(<\mathbf{0 . 0 0 0 1})\end{array}$ & $\begin{array}{l}-0.0401 \\
(<\mathbf{0 . 0 0 0 1})\end{array}$ & II \\
\hline & Sub-adult & $\begin{array}{l}0.1542 \\
(\mathbf{0 . 0 4})\end{array}$ & $\begin{array}{l}-0.0479 \\
(<\mathbf{0 . 0 0 0 1})\end{array}$ & II \\
\hline & Adult & $\begin{array}{l}-0.3691 \\
(0.0968)\end{array}$ & $\begin{array}{l}-0.0305 \\
(<\mathbf{0 . 0 0 0 1})\end{array}$ & II \\
\hline \multirow[t]{2}{*}{ (b) Experiment 2} & Simple & $\begin{array}{l}0.7931 \\
(<\mathbf{0 . 0 0 0 1})\end{array}$ & $\begin{array}{l}-0.0427 \\
(<\mathbf{0 . 0 0 0 1})\end{array}$ & II \\
\hline & Complex & $\begin{array}{l}-1.8046 \\
(<\mathbf{0 . 0 0 0 1})\end{array}$ & $\begin{array}{l}-0.0262 \\
(\mathbf{0 . 0 1 2 6})\end{array}$ & II \\
\hline
\end{tabular}

Table 3

One-way ANOVAs on attack rate $a$, handling time $h$ and maximum feeding rate $1 / h T$ in (a) Experiment 1 among E. marinus ontogenetic stages (juvenile, sub-adult and adult), and (b) Experiment 2 for adult E. marinus and small prey in simple and complex habitat. Significant $P$-values in bold, $\alpha=0.05$.

\begin{tabular}{|c|c|c|c|c|c|}
\hline & Source of variation & $d f$ & MS & $F$ & $P$ \\
\hline \multicolumn{6}{|c|}{ a) Experiment 1} \\
\hline \multirow[t]{2}{*}{$a$} & Ontogenetic stages & 2 & 8.885 & 43.66 & $<0.001$ \\
\hline & Error & 42 & 0.204 & & \\
\hline \multirow[t]{2}{*}{$h$} & Ontogenetic stages & 2 & 0.172 & 39.31 & $<0.001$ \\
\hline & Error & 42 & 0.004 & & \\
\hline \multirow[t]{2}{*}{$1 / h T$} & Ontogenetic stages & 2 & 0.221 & 38.95 & $<0.001$ \\
\hline & Error & 42 & 0.005 & & \\
\hline \multicolumn{6}{|c|}{ b) Experiment 2} \\
\hline \multirow[t]{2}{*}{$a$} & Habitat & 1 & 10.320 & 258.50 & $<0.001$ \\
\hline & Error & 28 & 0.040 & & \\
\hline \multirow[t]{2}{*}{$h$} & Habitat & 1 & 0.206 & 38.49 & $<0.001$ \\
\hline & Error & 28 & 0.005 & & \\
\hline \multirow[t]{2}{*}{$1 / h T$} & Habitat & 1 & 1.683 & 22.12 & $<0.001$ \\
\hline & Error & 28 & 0.076 & & \\
\hline
\end{tabular}

\subsection{Experiment 2}

Adult E. marinus, in both simple and complex habitat, were observed actively pursuing, capturing, killing and consuming the smallest size class of $J$. nordmanni. As before control J. nordmanni (no predator present) in each habitat type had $>99 \%$ survival after 24 h. Mean J. nordmanni deaths were significantly higher when E. marinus was present as compared to absent (Table 1b). There was a significant effect of 'habitat' (Table 1b), with more prey deaths in simple as compared to complex habitat (Fig. 3a). However, in both simple and complex habitats and at all prey densities, more prey died in the presence of E. marinus than in controls (Tukey's test, all $P<0.001$ ). There was also significantly more prey deaths at higher prey densities (Table 1b; Fig. 3a). A significant 'predator status $\times$ habitat' interaction (Table 1b; Fig. 3a) resulted from a greater disparity in deaths between experimental and control groups in simple as compared to complex habitat (Tukey's test, $P<0.05$ ), and a significant 'predator status $\times$ density' interaction (Table $1 \mathrm{~b}$; Fig. 3a) occurred due to greater disparities in deaths between experimental and control groups at higher densities (reflecting the $<1 \%$ deaths of prey when predators were absent).

Logistic regression indicated that adult E. marinus exhibited a Type II functional response towards the smallest size class of J. nordmanni in both habitat types, as revealed by the significantly negative linear coefficients (Table 2b; Fig. 3a and b). Mean attack rate $a$ was significantly higher in simple as compared to complex habitat (Table 3b; Fig. 4a), whilst mean handling time $h$ was significantly lower in simple compared to complex habitat (Table 3b; Fig. 4b). This corresponded to the mean maximum feeding rate $1 / h T$ being significantly higher in simple as compared to complex habitats (Table 3b; Fig. 4c).

\section{Discussion}

In this study, we found the isopod J. nordmanni in the guts of field caught amphipods, E. marinus, from juveniles through to adults, indicating that E. marinus utilises an active predatory feeding mode in the wild. Further, under laboratory conditions, juvenile, sub-adult and adult E. marinus exhibited Type II functional responses towards size-matched J. nordmanni prey. In addition, the largest adult E. marinus fed on the smallest J. nordmanni, again with Type II functional responses, in both homo- and heterogeneous habitats. As amphipod crustaceans are increasingly recognised as active predators (Bollache et al., 2008; Dick et al., 2005, 2012a; MacNeil et al., 1997), and marine inter-tidal communities are heavily influenced by predation, we have elucidated on the ontogeny of predation in the ubiquitous amphipod E. marinus. These results are important in a number of contexts. The 

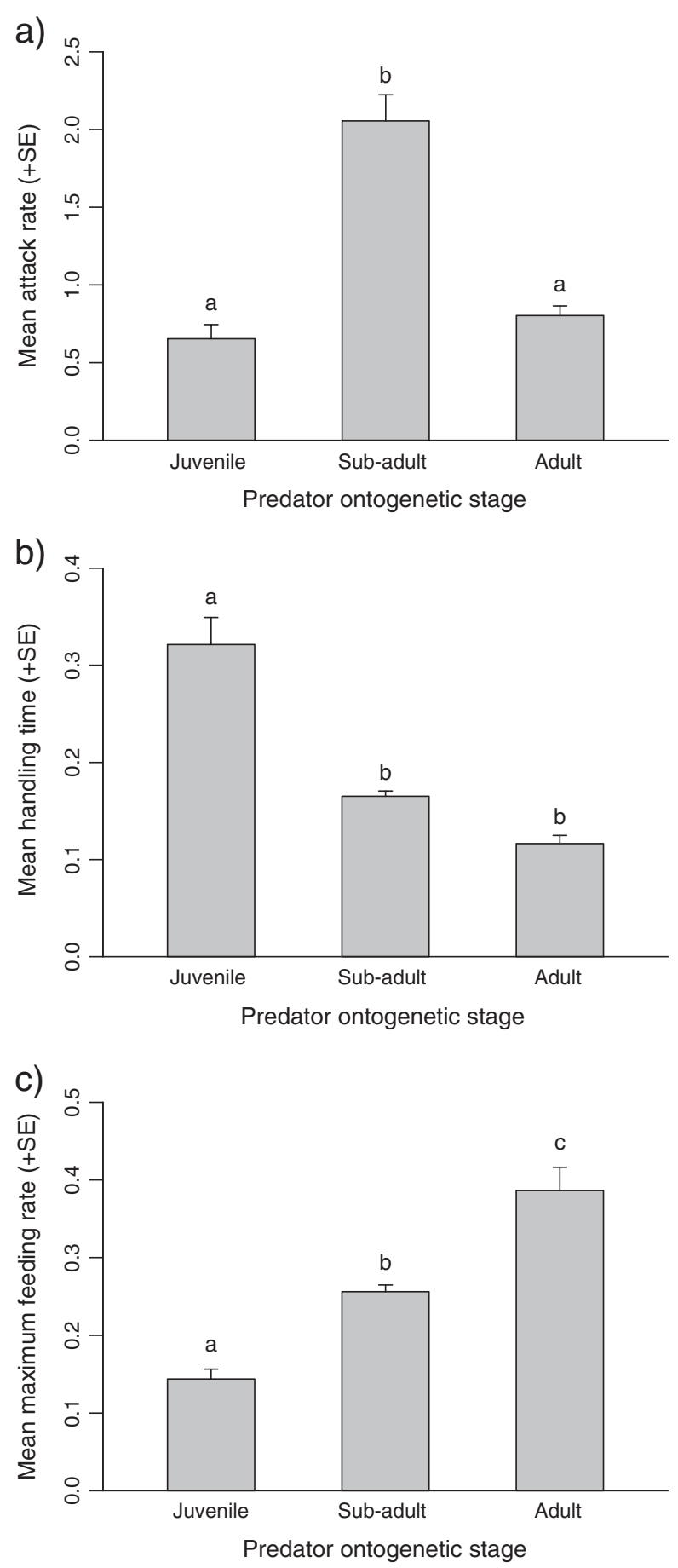

Fig. 2. Mean ( $+\mathrm{SE}$ ) (a) attack rate $a$, (b) handling time $h$ and (c) maximum feeding rate $1 / h T$ derived from bootstrapping ( $n=20$ each) juvenile, sub-adult and adult E. marinus consuming size matched J. nordmanni. Different letters indicate significant differences (Tukey's test, $P<0.05$ ).

impacts of predators on prey populations are generally considered with respect to only the adult predator or at a single point in the predator's life history (e.g. Micheli, 1997; Peckarsky, 1980; Turner, 2008). This is certainly true of the majority of functional response studies (e.g. Elliot, 2003; Iribarne et al., 1995; Koski and Johnson, 2002). It is likely, however, that a predator's capability and efficiency, as well as feeding modes and food types utilised, can change throughout ontogeny (Monteiro et al., 2005; St John, 1999). To fully understand a predator's effect on its prey, interactions over the full life-history range should be considered (Woodward and Warren, 2007). This may be of particular importance
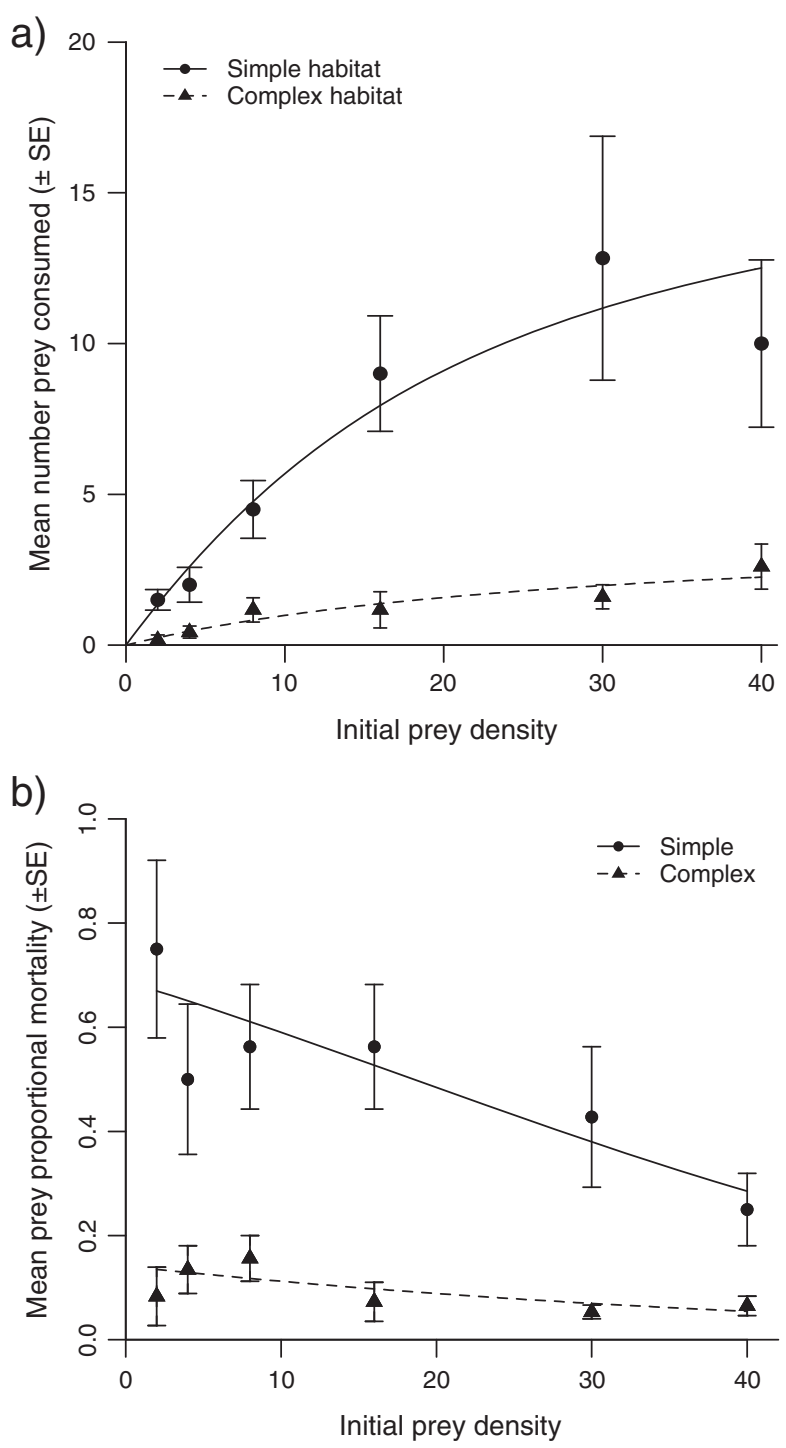

Fig. 3. (a) Functional responses of adult E. marinus towards J. nordmanni in simple and complex habitat. Means are numbers of prey consumed at each prey density, presented \pm SE. (b) Proportional mortality of J. nordmanni under predation from adult E. marinus in simple and complex habitat. Means are proportion of prey consumed at each prey density, presented with $\pm \mathrm{SE}$, and curves generated from first-order logistic regression analysis.

for species where there is increasing recognition of predatory capabilities in systems that are highly influenced by predatory processes (Connell, 1972; Maranhão et al., 2001; Menge, 1991).

Our gut content analysis from field caught $E$. marinus showed the presence of the isopod J. nordmanni in the diet of E. marinus at all ontogenetic stages, from juveniles not long emerged from the female brood pouch, to adults of maximum size. The occurrence of J. nordmanni in the gut of E. marinus could be the result of scavenging or accidental consumption when foraging on other resources. However, in our first experiment, we demonstrate in the laboratory that E. marinus is able to capture and consume J. nordmanni throughout ontogeny of the former from juvenile to adult, with significantly fewer prey surviving in the presence as compared to the absence of all sizes of E. marinus. Further, we found that, under laboratory conditions, E. marinus at each life-stage displayed Type II functional responses towards their prey when predator and prey body sizes were scaled to a constant ratio. This suggests that all life history stages of E. marinus are physically and behaviourally equipped to search for, capture, overpower and consume prey, which we also witnessed in many of the experimental replicates. 

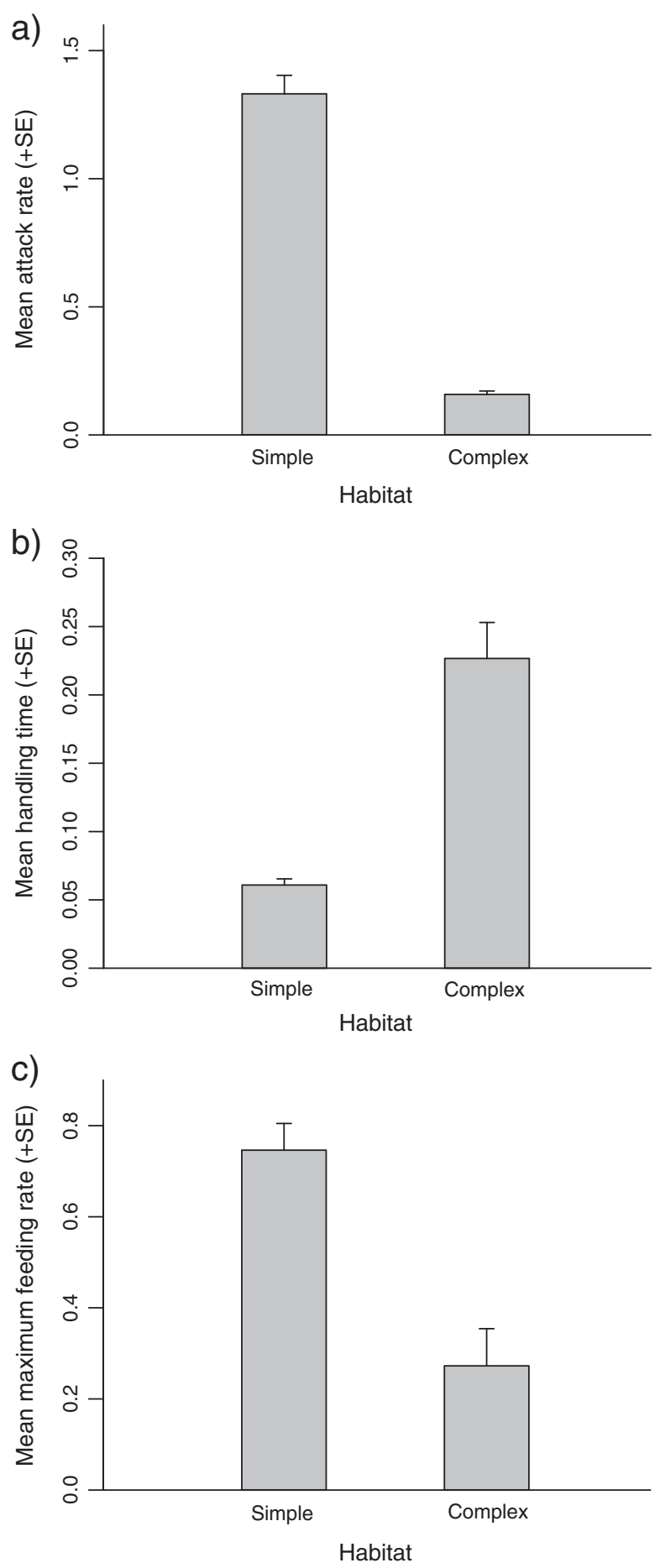

Fig. 4. Mean ( + SE) (a) attack rate $a$, (b) handling time $h$ and (c) maximum feeding rate $1 / h T$ derived from bootstrapping $(\mathrm{n}=20 \mathrm{each}$ ) adult $E$. marinus consuming J. nordmanni in simple and complex habitat.

Although classically referred to as the attack rate, $a$ is in fact the scaling parameter of the fitted functional response curve and describes the initial slope close to the origin (Hassell and May, 1973; Jeschke et al., 2002). An increase in this parameter is therefore indicative of greater predatory efficiency at lower prey densities, whereas a decrease suggests decreased efficiency. We found quite variable estimates of attack rate with no clear directional trend with predator size. This is contrary to other work that reported strong relationships between this parameter and size during ontogeny (Miller et al., 1992). Miller et al. (1992), however, maintained a constant prey size that was not scaled to the predator, as was in the current study. How the attack rate varies when the predator-prey size ratio is constant is not immediately obvious, however, but it is likely a function of allometry (see below). A significantly heightened attack parameter for sub-adult amphipods indicated a comparatively increased predatory efficiency at reduced prey densities. Sub-adult amphipods are possibly more motivated to search for and subsequently attack prey for a variety of potential reasons, such as increasing resource acquisition for the maintenance of growth, as well as costs associated with preparing for reproductive output (Dias and Hassall, 2005; Glazier, 2000). Resource acquisition is vital for growth rate and reductions in food uptake can lead to suppressed growth with implications for future fitness (Ball and Baker, 1996; Nakaoka, 2000; Pollock et al., 2005), and increased growth rates have been observed in younger amphipods with reduced rates towards the end of life (Neuparth et al., 2002).

In agreement with a number of studies in other systems (e.g. Altjetlawi et al., 2004; Elliot, 2005; McCoy and Bolker, 2008), increased handling time, $h$, corresponding to decreased maximum feeding rate, $1 / h T$, was observed in small juvenile amphipods. Handling time may be considered as a number of sub-components including time spent orientating to, pursuing and subduing prey. Subsequent to this, time will be spent eating and then digesting prey (Thompson, 1975). Although the predator-prey size ratio was constant, a number of aspects of the biology of juvenile amphipods may account for increased handling time leading to reduced feeding rate and overall reduced prey consumption in comparison to the other life stages. Predator experience can be important for individuals to become efficient foragers (Flynn and Ritz, 1999; Reid et al., 2010; Rovero et al., 1999), and juvenile amphipods may be less familiar with the prey in comparison to sub-adult and adult amphipods that have had greater opportunity for prey learning. Specifically, predators with experience at prey manipulation should be at an advantage in the initial stages of handling (Croy and Hughes, 1991). In the subsequent stages of consumption and digestion, smaller predators may be at a further disadvantage and less able to process prey. Although the prey size was scaled for predator body size, studies have suggested that digestive processing constraints may be more important in small individuals compared to large ones (Penry and Jumars, 1990). Chitinous crustacean exoskeletons in particular have been shown to be poorly digestible in larval fish and to have variable passage rates through the gut (Conway et al., 1993). Furthermore, it should be considered that while we scaled predators and prey by length, this is a linear measure. Intestinal length and gut volume has been shown to follow an allometric relationship (Kramer and Bryant, 1995) and this may have constrained prey consumption by the smaller, juvenile predators further.

In our second experiment, we found that there is no size refuge for smaller prey body sizes from the largest adult predators and that $E$. marinus significantly reduces such prey numbers in both simple and complex habitats. However, although habitat complexity significantly reduced the number of prey items consumed over all, a Type II functional response was observed in adult E. marinus feeding on the smallest isopod size-class in both the presence and absence of habitat complexity. Even though the occurrence of a Type III functional response is frequently documented under such environmental conditions (Buckel and Stoner, 2000; Kushner and Hovel, 2006; Lipcius and Hines, 1986), such a change in response does not always occur (Dittel et al., 1995; Long et al., 2012). This is of particular importance due to the contributions each response type (II and III) makes to prey population stability. Type II responses are considered de-stabilising, owing to the consumption of most if not all prey at low densities, whereas Type III responses are considered to impart stability, allowing prey to persist at low densities due to a suppression of predator consumption (Rindone and Eggleston, 2011; Seitz et al., 2001; Wennhage, 2002).

In aquatic communities, body size of both prey and predator is an important attribute that is directly linked to foraging success. Predators 
may become more successful with increasing size due to a variety of factors such as better visual acuity (Miller et al., 1993) and increased foraging capabilities with experience (Croy and Hughes, 1991). However, predator growth may also limit feeding ability at the lower end of the prey size spectrum, such that larger predators are physically unable to capture smaller prey (e.g. Rindone and Eggleston, 2011; Stevens and Swiney, 2005). Related to this, a predator may out-grow smaller prey items due to factors relating to increased cost of consumption in relation to net benefits, and optimal foraging models predict that large predators should concentrate on larger prey (Gill, 2003; Stephens and Krebs, 1986). Indeed, prey size generally increases with predator size in marine ecosystems (Costa, 2009), and smaller prey individuals may therefore experience a size refuge from larger predators (Allan, 1978; Muotka et al., 1999; Newman and Waters, 1984). Conversely, however, as is suggested in the present study, prey that are small relative to the predator may require less time to subdue, eat and digest (Lundvall et al., 1999; Ryer, 1988), which would result in a predator with a reduced handling time and increased feeding rate. Here, large adult E. marinus consumed small prey sizes at an increased rate in comparison to all other treatments, which is driven by an associated reduced handling time (c.f. Figs. 1a and 3a). Similarly, large E. marinus showed greater attack efficiencies at low prey densities compared to other size pairings, albeit reduced in comparison to medium, sub-adult predators, as well as increased attack rates towards small prey sizes in simple habitats. Such a feeding rate by large, adult predators has implications for the prey population that is also readily consumed by small, juvenile predators as it may therefore be assumed that all predator sizes within this range are further contributing to this predation pressure on small prey sizes.

We have demonstrated here that active predation by the marine intertidal amphipod E. marinus is conserved throughout its life history, from juvenile through to sub-adult and adult life-stages, thus further countering the traditional classification of such amphipod taxa as purely herbivorous 'shredders' (Kelly et al., 2002; MacNeil et al., 1997). This has consequences for the stability of prey populations which are susceptible to predation throughout the ontogeny of the amphipod, however, as E. marinus is not an obligate feeder on J. nordmanni and has been demonstrated to feed on a variety of food types including animal and algal species (Dick et al., 2005), an ease of pressure on the isopod population may be expected if prey switching occurs (Murdoch, 1969; Akre and Johnson, 1979). The use of functional responses shown here in the context of ontogeny has, however, allowed us to further understand this predator-prey interaction. It has provided a useful tool for the investigation and comparison of feeding behaviours over the course of the lifetime of E. marinus and is a valuable approach for aiding our understanding of the dynamics of amphipod interactions with their prey and the structuring of marine littoral communities. Further work should examine shifts in such interactions in response to changing conditions with respect to such communities, such as global climate change (Taylor and Collie, 2003) and invasive species (Dick et al., 2012a, 2012b; Haddaway et al., 2012), especially as amphipods feature as global invaders (Conlan, 1994; Dick and Platvoet, 2000).

\section{Acknowledgements}

We would like to thank Gillian Riddell for assistance in field sampling. We would also like to thank the following for their invaluable input on statistical analyses: Ruth Kelly, Olga Lyashevska, Jim Hawkins, Russell Thompson and Jonathan Jeschke. This study was completed as part of a PhD, funded by the Department for Education and Learning Northern Ireland. [RH]

\section{References}

Akre, B.G., Johnson, D.M., 1979. Switching and sigmoid functional response curves by damselfly naiads with alternative prey available. J. Anim. Ecol. 48, 703-720.
Alexander, M.E., Dick, J.T.A., O'Connor, N.E., Haddaway, N.R., Farnsworth, K.D., in press Functional responses of the intertidal amphipod Echinogammarus marinus: effects of prey supply, model selection and habitat complexity. Mar. Ecol. Prog. Ser.

Allan, J.D., 1978. Trout predation and the size composition of stream drift. Limnol. Oceanogr. 23, 1231-1237.

Almany, G.R., 2004. Does increased habitat complexity reduce predation and competition in coral reef assemblages? Oikos 106, 275-284.

Altjetlawi, A.A., Sparrevik, E., Leonardsson, K., 2004. Prey-predator size-dependent functional response: derivation and rescaling to the real world. J. Anim. Ecol. 73, 239-252.

Ball, S.L., Baker, R.L., 1996. Predator-induced life history changes: antipredator behaviour costs or facultative life history shifts? Ecology 77, 1116-1124.

Bolker, B.M., 2010. emdbook: Ecological models and data in R. R Package.

Bollache, L., Dick, J.T.A., Farnsworth, K.D., Montgomery, W.I., 2008. Comparison of the functional responses of invasive and native amphipods. Biol. Lett. 4, 166-169.

Brawley, S.H., Adey, W.H., 1981. The effect of micrograzers on algal community structure in a coral reef microcosm. Mar. Biol. 61, 167-177.

Buckel, A., Stoner, A.W., 2000. Functional response and switching behavior of youngof-the-year piscivorous bluefish. J. Exp. Mar. Biol. Ecol. 245, 25-41.

Caldow, R.W.G., Furness, R.W., 2001. Does Holling's disc equation explain the functiona response of a kleptoparasite? J. Anim. Ecol. 70, 650-662.

Céréghino, R., 2006. Ontogenetic diet shifts and their incidence on ecological processes, a case study using two morphologically similar stoneflies (Plecoptera). Acta Oecol. 30, 33-38.

Colton, T.F., 1987. Extending functional response models to include a second prey type: an experimental test. Ecology 68, 900-912.

Conlan, K.E., 1994. Amphipod crustaceans and environmental disturbance: a review. J. Nat. Hist. 28, 519-554.

Connell, J.H., 1972. Community interactions on marine rocky intertidal shores. Ann Rev. Ecol. Syst. 3, 169-192.

Conway, D.V.P., Tranter, P.R.G., Coombs, S.H., 1993. Digestion of natural food by larval and post-larval turbot Scophythalmus maximus. Mar. Ecol. Prog. Ser. 100, 221-231.

Costa, G.C., 2009. Predator size, prey size, and dietary niche breadth relationships in marine predators. Ecology 90, 2014-2019.

Côté, I.M., Jelnikar, E., 1999. Predator-induced clumping behaviour in mussels (Mytulus edulis Linnaeus). J. Exp. Mar. Biol. Ecol. 235, 201-211.

Croy, M.I., Hughes, R.N., 1991. The role of learning and memory in the feeding behaviour of the fifteen-spined Spinachia spinachia L. Anim. Behav. 41, 149-159.

Dias, N., Hassall, M., 2005. Food, feeding and growth rates of peracarid macrodecomposers in a Ria Formosa salt marsh, southern Portugal. J. Exp. Mar. Biol. Ecol. 325, 84-94.

Dick, J.T.A., Platvoet, D., 2000. Invading predatory crustacean Dikerogammerus villosus eliminates both native and exotic species. Proc. R. Soc. Lond. B. 267, 977-983.

Dick, J.T.A., Johnson, M.P., McCambridge, S., Johnson, J., Carson, V.E.E., Kelly, D.W., MacNeil, C., 2005. Predatory nature of the littoral amphipod Echinogammarus marinus: gut content analysis and effects of alternative food and substrate heterogeneity. Mar. Ecol. Prog. Ser. 291, 151-158.

Dick, J.T.A., Alexander, M.E., MacNeil, C., 2012a. Natural born killers: an invasive amphipod is predatory throughout its life-history. Biol. Invasions. http://dx.doi.org/ 10.1007/s10530-012-0287-9.

Dick, J.T.A., Gallagher, K., Avlijas, S., Clarke, H.C., Lewis, S.E., Leung, S., Minchin, D., Caggrey, J., Alexander, M.E., Maguire, C., Harrod, C., Reid, N., Haddaway, N., Farnsworth, K.D., Penk, M., 2012b. Ecological impacts of an invasive predator explained and predicted by comparative functional responses. Biol. Invasions. http://dx.doi.org/10.1007/ s10530-012-0332-8.

Dittel, A.I., Hines, A.H., Ruiz, G.M., Ruffin, K.K., 1995. Effects of shallow water refuge on behaviour and density dependent mortality of juvenile blue crabs in Chesapeake Bay. Bull. Mar. Sci. 57, 902-916.

Duffy, J.E., Hay, M.E., 2000. Strong impacts of grazing amphipods on the organisation of a benthic community. Ecol. Monogr. 70, 237-263.

Dunn, A.M., Dick, J.T.A., 1998. Parasitism and epibiosis in the invasion of non-native gammarids in freshwater in Ireland. Ecography 21, 593-598.

Elliot, J.M., 2003. Interspecific interference and the functional response of four species of carnivorous stoneflies. Freshw. Biol. 48, 1527-1539.

Elliot, J.M., 2005. Ontogenetic shifts in the functional response and interference interactions of Rhyacophila dorsalis larvae (Trichoptera). Freshw. Biol. 50, 2021-2033.

Emmerson, M.C., Raffaelli, D., 2004. Predator-prey body size, interaction strength and the stability of a real food web. J. Anim. Ecol. 73, 399-409.

Flynn, A.J., Ritz, D.A., 1999. Effect of habitat complexity and predatory style on the capture success of fish feeding on aggregated prey. J. Mar. Biol. Ass. U.K. 79, 487-494

Fox, L.R., Murdoch, W.W., 1978. Effects of feeding history on short-term and long-term functional responses in Notonecta hoffmanni. J. Anim. Ecol. 47, 945-959.

Gill, A.B., 2003. The dynamics of prey choice in fish: the importance of prey size and satiation. J. Fish Biol. 63, 105-116.

Glazier, D.S., 2000. Is fatter fitter? Body storage and reproduction in ten populations of the freshwater amphipod Gammarus minus. Oecologia 122, 335-345.

Graeb, B.D.S., Mangan, M.T., Jolley, J.C., Wahl, D.H., Dettmers, J.M., 2006. Ontogenetic changes in prey preference and foraging ability of yellow perch: insights based on relative energetic return of prey. Trans. Am. Fish. Soc. 135, 1493-1498.

Haddaway, N.R., Wilcox, R.H., Heptonstall, R.E.A., Griffiths, H.M., Mortimer, R.J.G., Christmas, M., Dunn, A.M., 2012. Predatory functional response and prey choice identify predation differences between native/invasive and parasitised/unparasitised crayfish. PLoS One 7 (2), e32229.

Hanquet, D., Legalle, M., Garbage, S., Céréghino, R., 2004. Ontogenetic microhabitat shifts in stream invertebrates with different biological traits. Arch. Hydrobiol. $160,329-346$ 
Hassell, M.P., 1978. The Dynamics of Arthropod Predator-Prey Systems. Princeton University Press, Princeton.

Hassell, M.P., May, R.M., 1973. Stability in insect host-parasite models. J. Anim. Ecol. 42, 693-726.

Holling, C.S., 1959. Some characteristics of simple types of predation and parasitism. Can. Entomol. 91, 385-398.

Ingólfsson, A., Agnarsson, I., 1999. Anonyx sarsi: a major unrecognized scavenger and predator in the intertidal zone. J. Mar. Biol. Ass. UK 79, 1127-1128.

Iribarne, O., Armstrong, D., Fernández, M., 1995. Environmental impact of intertidal juvenile dungeness crab habitat enhancement: effects on bivalves and crab foraging rate. J. Exp. Mar. Biol. Ecol. 192, 173-194.

Jennions, M.D., Backwell, P.R.Y., Murai, M., Christy, J.H., 2003. Hiding behavior in fiddler crabs: how long should prey hide in response to a potential predator? Anim. Behav. 66, 251-257.

Jeschke, J.M., Hohberg, K., 2008. Predicting and testing functional responses: an example from a tardigrade-nematode system. Basic Appl. Ecol. 9, 145-151.

Jeschke, J.M., Kopp, M., Tollrian, R., 2002. Predator functional responses: discriminating between handling and digesting prey. Ecol. Monog. 72, 95-112.

Juliano, S.A., 2001. Nonlinear curve fitting: predation and functional response curves. In: Scheiner, S.M., Gurevitch, J. (Eds.), Design and Analysis of Ecological Experiments. Oxford University Press, Oxford, pp. 178-196.

Kelly, D.W., Dick, J.T.A., Montgomery, W.I., 2002. The functional role of Gammarus (Crustacea, Amphipoda): shredders, predators, or both? Hydrobiologia 485, 199-203.

Koski, M.L., Johnson, B.M., 2002. Functional response of kokanee salmon (Oncorhynchus nerka) to Daphnia at different light levels. Can. J. Fish. Aquat. Sci. 59, 707-716.

Kramer, D.L., Bryant, M.J., 1995. Intestine length in the fishes of a tropical stream: 1 : Ontogenetic allometry. Environ. Biol. Fish. 42, 115-127.

Kushner, R.B., Hovel, K.A., 2006. Effects of native predators and eelgrass habitat structure on the introduced Asian mussel Musculista senhousia (Benson in Cantor) in southern California. J. Exp. Mar. Biol. Ecol. 332, 166-177.

Lipcius, R.N., Hines, A.H., 1986. Variable functional responses of a marine predator in dissimilar homogenous microhabitats. Ecology 67, 1361-1371.

Long, W.C., Popp, J., Swiney, K.M., Van Sant, S.B., 2012. Cannibalism in red king crab, Paralithodes camtschaticus (Tilesius, 1815): effects of habitat type and predator density on predator functional response. J. Exp. Mar. Biol. Ecol. 422-423, 101-106.

Lundvall, D. Svanbäck, R. Persson, L., Byström, P. 1999. Size-dependent predation in piscivores: interactions between predator foraging and prey avoidance abilities. Can. J. Fish. Aquat. Sci. 56, 1285-1292.

MacNeil, C., Dick, J.T.A., Elwood, R.W., 1997. The trophic ecology of freshwater Gammarus spp. (Crustacea: Amphipoda): problems and perspectives concerning the functional feeding group concept. Biol. Rev. 72, 349-364.

Maranhão, P., Bengala, N., Pardal, M., Marques, J.C., 2001. The influence of environmental factors on the population dynamics, reproductive biology and productivity of Echinogammarus marinus Leach (Amphipoda, Gammaridae) in the Mondego estuary (Portugal). Acta Oecol. 22, 139-152.

McCoy, M.W., Bolker, B.B., 2008. Trait-mediated interactions: influence of prey size, density and experience. J. Anim. Ecol. 77, 478-486.

Menge, B.A., 1991. Relative importance of recruitment and other causes of variation in rocky intertidal community structure. J. Exp. Mar. Biol. Ecol. 146, 69-100.

Micheli, F., 1997. Effects of predator foraging behaviour on patterns of prey mortality in marine soft bottoms. Ecol. Monogr. 67, 203-224.

Miller, T.J., Crowder, L.B., Rice, J.A., 1992. Body size and the ontogeny of the functional response in fishes. Can. J. Fish. Aquat. Sci. 49, 805-812.

Miller, T.J., Crowder, L.B., Rice, J.A., 1993. Ontogenetic changes in behavioural and histological measures of visual acuity in three species of fish. Environ. Biol. Fishes 37, $1-8$.

Monteiro, H.M., Quinteira, S.M., Silva, K., Vieira, M.N., Almada, V.C., 2005. Diet preference reflects the ontogenetic shift in microhabitat use in Lipophrys pholis. J. Fish Biol. 67, 102-113.

Morato, T., Santos, R.S., Andrade, J.P., 2000. Feeding habits, seasonal and ontogenetic diet shift of blacktail comber, Serranus atricauda (Pisces: Serranidae), from the Azores, north-eastern Atlantic. Fish. Res. 49, 51-59.

Muotka, T., Huhta, A., Tikkanen, P., 1999. Diel vertical movements by lotic mayfly nymphs under variable predation risk. Ecol. Entomol. 24, 443-449.

Murdoch, W.W., 1969. Switching in general predators: experiments on predator specificity and stability of prey populations. Ecol. Monogr. 39, 335-354.

Murdoch, W.W., Oaten, A., 1975. Predation and population stability. Adv. Ecol. Res. 9, $1-131$.

Nakaoka, M., 2000. Nonlethal effects of predators on prey populations: predatormediated change in bivalve growth. Ecology 81, 1031-1045.
Neuparth, T., Costa, F.O., Costa, M.H., 2002. Effects of temperature and salinity on life history of the marine amphipod Gammarus locusta. Implications for ecotoxicological testing. Ecotoxicology 11, 61-73.

Newman, R.M., Waters, T.F., 1984. Size-selective predation on Gammarus pseudolimnaeus by trout and sculpins. Ecology 65, 1535-1545.

O'Brien, C.J., 1994. Ontogenetic changes in the diet of juvenile brown tiger prawns Penaeus esculentus. Mar. Ecol. Prog. Ser. 112, 195-200.

O'Gorman, E.J., Emmerson, M.C., 2011. Body mass-abundance relationships are robust to cascading effects in marine food webs. Oikos 120, 520-528.

Peckarsky, B.L., 1980. Predator-prey interactions between stoneflies and mayflies: behavioural observations. Ecology 61, 932-943.

Penry, D.L., Jumars, P.A., 1990. Gut architecture, digestive constraints and feeding ecology of deposit-feeding and carnivorous polychaetes. Oecologia 82, 1-11.

Pollock, M.S., Zhao, X., Brown, G.E., Kusch, R.C., Pollock, R., Chivers, D.P., 2005. The response of convict cichlids to chemical alarm cues: an integrated study of behaviour, growth and reproduction. Ann. Zool. Fennici. 42, 485-495.

R Development Core Team, 2011. R: Language and Environment for Statistical Computing. Austria, Vienna. ISBN 3-900051-07-0, http://www.R-project.org.

Reid, A.L., Seebacher, F., Ward, A.J.W., 2010. Learning to hunt: the role of experience in predator success. Behav. 147, 223-233.

Rindone, R.R., Eggleston, D.B., 2011. Predator-prey dynamics between recently established stone crabs (Menippe spp.) and oyster prey (Crassotrea virginica). J. Exp. Mar. Biol. Ecol. 407, 216-225.

Rogers, D., 1972. Random search and insect population models. J. Anim. Ecol. 41, 369-383.

Rovero, F., Hughes, R.N., Chelazzi, G., 1999. Effect of experience on predatory behaviour of dogwhelks. Anim. Behav. 57, 1241-1249.

Ryer, C.H., 1988. Pipefish foraging: effects of fish size, prey size and altered habitat complexity. Mar. Ecol. Prog. Ser. 48, 37-45.

Seitz, R.D., Lipcius, R.N., Hines, A.H., Eggleston, D.B., 2001. Density-dependent predation, habitat variation, and the persistence of marine bivalve prey. Ecology 82, 2435-2451.

St John, J., 1999. Ontogenetic changes in the diet of the coral reef grouper Plectropomus leopardus (Serranidae): patterns in taxa, size and habitat of prey. Mar. Ecol. Prog. Ser. $180,233-246$.

Stephens, D.W., Krebs, J.R., 1986. Foraging Theory. Princeton University Press, Princeton, Inc., NJ, USA.

Stevens, B.G., Swiney, K.M., 2005. Post-settlement effects of habitat type and predator size on cannibalism of glaucothoe and juveniles of red king crab Paralithodes camtschaticus. J. Exp. Mar. Biol. Ecol. 32, 1-11.

Swisher, B.J., Soluk, D.A., Wahl, D.H., 1998. Non-additive predation in littoral habitats: influences of habitat complexity. Oikos 81, 30-37.

Taylor, D.L., Collie, J.S., 2003. Effect of temperature on the functional response and foraging behavior of the sand shrimp Crangon septemspinosa preying on juvenile winter flounder Pseudopleuronectes americanus. Mar. Ecol. Prog. Ser. 263, 217-234.

Thompson, D.J., 1975. Towards a predator-prey model incorporating age structure: the effects of predator and prey size on the predation of Daphnia magna by Ischnura elegans. J. Anim. Ecol. 44, 907-916.

Trexler, J.C., McCulloch, C.E., Travis, J., 1988. How can the functional response best be determined? Oecologia 76, 206-214.

Turner, A.M., 2008. Predator diet and prey behavior: freshwater snails discriminate among closely related prey in a predator's diet. Anim. Behav. 76, 1211-1217.

Underwood, A.J., 1997. Experiments in Ecology. Cambridge University Press, Cambridge.

Warfe, D.M., Barmuta, L.A., 2004. Habitat structural complexity mediates the foraging success of multiple predator species. Oecologia 156, 515-522.

Wennhage, H., 2002. Vulnerability of newly settled plaice (Pleuronectes platessa L.) to predation: effects of habitat structure and predator functional response. J. Exp. Mar. Biol. Ecol. 269, 129-145.

Werner, E.E., Gilliam, J.F., 1984. The ontogenetic niche and species interactions in sizestructured populations. Ann. Rev. Ecol. Syst. 15, 393-425.

Werner, E.E., Hall, D.J., 1988. Ontogenetic habitat shifts in bluegill: the foraging ratepredation risk trade-off. Ecology 69, 1352-1366.

Wilson, D.S., 1975. The adequacy of body size as a niche difference. Am. Nat. 109, 769-784.

Woodward, G., Hildrew, A.G., 2002. Body-size determinants of niche overlap and intraguild predation within a complex food web. J. Anim. Ecol. 71, 1063-1074.

Woodward, G., Warren, P., 2007. Body size and predatory interactions in freshwaters: scaling from individuals to communities. In: Hildrew, A.G., Raffaelli, D.G., EdmondsBrown, R. (Eds.), Body Size: The Structure and Function of Aquatic Communities. Cambridge University Press, Cambridge, pp. 98-117. 